12-Laryngology, Rhinology, Otology, and Stomatology.

13-Obstetrics and Gynæcology.

14-Hygiene and Epidemiology.

15-Military Medicine.

16-Legal iredicine.

17-Colonial and Naval Medicine.

The Fxecutive Committee of the Congress will print, before the Cungress opens, all the official reports; it is therefore necessaly that they should be forwarded before September 30, 1905, to the General Secretary. Other communications should be forwarderl before December 31, 1905, if the authors desire their conclusions printed before the opening of the Congress.

The official language is French. In the general assemblies, in well as in the sections, English, German, and French may be nserl. We note that the Committee of the Congress has excluded the Portuguese from the official languages; this has obviously been done with the intention of diminishing the number of languages.

The President of the Committee of Organisation is Dr. M. dia Costa Alemao; the General Secretary is Dr. Miguel Bombardia; all adhesions must be addressed to the latter at the Hospital di Rilhafolles, Lisbon.

The following gentlemen form the Committee of Section 1:. Laryngology, Rhinology, Otology and Stomatology :

Président-M. Gregorio Fernandes. Secretaries-M. Avelin" Monteiro, M. Caldeira Cabral. Membres-MII. Amor de Mellu, Manoel Valladares, Manuel Caroça, Sant'Anna Leite.

\title{
A CASE OF DEAFNESS FOLLOWING ON NASAL OBSTRUCTION WITHOUT OTHER DISEASE OF THE HEARING APPARATUS.
}

By Dr. Wallace Mackenzie, Wellington, N.Z.

A. P-WAs mander my treatment in the out-patient department of the Wellington District Hospital during February, 1897, on accoulit of deafness in both ears.

His father died of cancer of the larynx at about fifty-seven years of age, otherwise his family history was good. The patient was a strong, healthy man twenty-four years of age. Five months previously he had had his nose treated with the galvano-cautery because he had a difficulty in breathing through it when he had : cold. After the treatment the nasal obstruction became almost 
complete, and when I saw him he had become very deaf. He was sure that hearing was perfect before undergoing the treatment.

On examination both nostrils were closed by adhesion of the isternal walls to the septum. A little air could be blown out, but none drawn in through the nose, and a probe entered beyond the whstruction, along the superior fossa on each side. The fances, pharynx, and naso-pharynx were healthy, and both tympanic memliranes were somewhat indrawn.

On testing the hearing, he heard loud spoken words at each ear. He conld not hear a large " $\mathrm{C}^{l}$ " tuning fork by air conduction, while bone conduction was quite equal to normal on both sides.

I decided to first get clear passages through the nose, so took the patient into the hospital. Dr. Ewart gave chloroform, and, fassing a probe-pointed bistoury past the adhesions abore, I cut straight down to the floor of the nose, as it was impossible to find the old passage.

Bleeding was free and required to be controlled by plugging with gauze. On the right side the dividing knife had entered the lower part of the inferior meatus, which had not become adherent, but on the left side the raw surface extended right into the floor of the nose. On the floor and outer side of the left nostril I planted a piece of mucous membrane from the inside of the under lip, and un both sides inserted a long slip of celluloid from a photographic tilm to prevent adhesions forming again. Healing took place readily, and the patency of the cavities of the nose was soon re-established.

A fortnight after the operation hearing was distinctly better, and the improvement was noticed suddenly. Dr. Ewart, the medical superintendent of the hospital, drew my attention to the sudden and remarkable improvement in the man's hearing.

I saw the patient again on November 22 2 last. I tested his hearing from a low " $\mathrm{C}$ " tuning fork to the highest note given by my "Galton's whistle." I also tested his bone conduction, and the relation between bone and air conduction, and found his hearing in these respects normal. Testing with the watch and spoken roice showed the hearing distance to be up to the average, and the range if hearing good.

It is a matter of common observation that a person may have the nose completely blocked with polypus and yet retain good hearing, and when deafness accompanies polypus of the nose it is issociated usually with mucus in the middle ears, but the whole enviromment of nasal polypus is tutally different to a simple noninfianmatory obstruction of the nose. 
A case is reported in the Annales des Maladies de l'Oreille, tu Larynx, du Nez, et du Pharynx, January, 1894, in which a bony obstruction caused deafness; on removal of the obstruction the deafness was much improved. There has been a considerable number of similar cases reported since, and I have no doubt that it will come to be generally recognised that certain cases of nasal obstruition lead to deafness directly, and the reason for the deafness will be pointed out.

\title{
THE GALYANO-CAUTERY IN THE TREATMENT OF INTRA- LARYNGEAL GROWTHS.
}

\author{
By Dr. Dendas Grant, F.R.C.S., \\ Surgeon to the Central London Throat Hospital.
}

The final remoral of the stump of an intra-laryngeal growth is often as difficult as (to the expert) that of the main mass of it is easy. Oliver Wendell Holmes's happy analogy between the elaboration of the last few lines of a poem and the extraction of the last drops of oil out of a bottle is fairly applicable to the case in point. Such at least has been the experience of the writer.

Many valuable forms of intra-laryngeal forceps are at the disposal of the operator, and I believe that the form devised by myself for cutting growths off the edge of the vocal cord, the description of which appeared in the Lancet of June 3, 189:3, has been in very general use for the intended purpose within the limits which the slightest consideration would impose. For growths on the upper surface of the cord it is of course inapplicable, and for these the form devised by the late McNeill Whistler is the most efficacious for those who have been accustomed to Mackenzie's instruments. These are available also for many growths in the anterior commissure, though here the snare (so strongly advocat'd by the late Lennox Browne) has its seat of election. Forceps with the tips bent forwards according to the designs of Lambert Lack and Fitzgerald Powell will often clear the anterior commissure when other instruments fail. The extirpation of the residual stump from which regrowth is very apt to take place often baftles instrumental interference, as, for instance, when the growth is on the edge of the vocal cord, but so near the anterior commissure that there is no room in front of it for the anterior blade of cleancutting forceps. Such was the case in two instances lately under 